\title{
Prognostic significance of clinicopathological factors in early breast cancer: 20 years of follow-up in a single-center analysis
}

\author{
Valentina Cocciolone ${ }^{1,2}$, Katia Cannita ${ }^{1}$, Maria Letizia Calandrella ${ }^{1}$, Enrico \\ Ricevuto ${ }^{2,3}$, Paola Lanfiuti Baldi ${ }^{1}$, Tina Sidoni ${ }^{1}$, Azzurra Irelli ${ }^{1}$, Stefania Paradisi ${ }^{1}$, \\ Laura Pizzorno ${ }^{4}$, Valter Resta ${ }^{4}$, Alberto Bafile ${ }^{4}$, Edoardo Alesse ${ }^{2}$, Alessandra \\ Tessitore $^{2}$ and Corrado Ficorella ${ }^{1,2}$ \\ ${ }^{1}$ Medical Oncology, S. Salvatore Hospital, University of L'Aquila, Via Vetoio, 67100 L'Aquila, Italy \\ ${ }^{2}$ Department of Biotechnological and Applied Clinical Sciences, University of L'Aquila, Via Vetoio, 67100 L'Aquila, Italy \\ ${ }^{3}$ Oncology Network ASL1 Abruzzo, UOSD Oncology Territorial Care, S. Salvatore Hospital, University of L'Aquila, Via Vetoio, \\ 67100 L'Aquila, Italy \\ ${ }^{4}$ Breast Unit, S. Salvatore Hospital, L'Aquila, Via Vetoio, 67100 L'Aquila, Italy
}

Correspondence to: Valentina Cocciolone, email: vale.cocciolone@tiscali.it

Keywords: clinicopathological prognostic factors, early breast cancer, clinical practice, survival, 20-year follow-up

Received: November 08, 2016

Accepted: June 02, 2017

Published: June 16, 2017

Copyright: Cocciolone et al. This is an open-access article distributed under the terms of the Creative Commons Attribution License 3.0 (CC BY 3.0), which permits unrestricted use, distribution, and reproduction in any medium, provided the original author and source are credited.

\section{ABSTRACT}

Background: To quantify the effect of traditional prognostic factors [nodal status, estrogen-receptor (ER), progesterone-receptor (PR), human epidermal growth factor receptor 2 (HER2)] on long-term outcome of patients with early breast cancer (EBC), treated in clinical practice over a period of about twenty years.

Results: 1198 consecutive patients were identified. Median DFS (disease-free survival): ER+/PR \pm /HER2-, 165 months (mo) if node-negative (NO) and $114 \mathrm{mo}$ if node-positive $(N+)(p<0.001)$; triple-negative (TN), 109mo if $N 0$ and $65 \mathrm{mo}$ if $N+(p$ $0.144) ; E R+/ P R \pm / H E R 2+$ in patients not-treated with adjuvant trastuzumab ( $T-)$, not reached if $N O$ and $114 \mathrm{mo}$ if $\mathrm{N}+(\mathrm{p} \mathrm{0.297}) ; \mathrm{ER}+/ \mathrm{PR} \pm / \mathrm{HER2}+$ in patients treated with trastuzumab $(\mathrm{T}+), 95 \mathrm{mo}$ if $\mathrm{NO}$ and $85 \mathrm{mo}$ if $\mathrm{N}+(\mathrm{p} \mathrm{0.615}) ; \mathrm{ER}-/ \mathrm{PR}-/ \mathrm{HER} 2+\mathrm{T}-$, not reached if $\mathrm{NO}$ and $26 \mathrm{mo}$ if $\mathrm{N}+(\mathrm{p} \mathrm{0.279})$; $\mathrm{ER}-/ \mathrm{PR}-/ \mathrm{HER} 2+\mathrm{T}+$, not reached if $\mathrm{NO}$ and $66 \mathrm{mo}$ if $\mathrm{N}+(\mathrm{p}$ 0.014). Median OS (overall survival): ER+/ PR \pm /HER2-, 166mo if $\mathrm{NO}$ and $144 \mathrm{mo}$ if $\mathrm{N}+(\mathrm{p} \mathrm{0.028}) ; \mathrm{TN}, 158 \mathrm{mo}$ if $\mathrm{NO}$ and $96 \mathrm{mo}$ if $\mathrm{N}+(\mathrm{p} \mathrm{0.384}) ; \mathrm{ER}+/ \mathrm{PR} \pm /$ HER2+ $T-$, not reached if $N 0$ and $157 \mathrm{mo}$ if $\mathrm{N}+(\mathrm{p} \mathrm{0.475}), \mathrm{ER}+/ \mathrm{PR} \pm / \mathrm{HER} 2+\mathrm{T}+$, not reached if $\mathrm{NO}$ and $106 \mathrm{mo}$ if $\mathrm{N}+(\mathrm{p} \mathrm{0.436)}$; ER-/PR-/HER2+ T-, not reached if NO and 34mo if $\mathrm{N}+(\mathrm{p} \mathrm{0.273})$; $E R-/ P R-/ H E R 2+T+$, not reached neither if NO nor if $\mathrm{N}+(\mathrm{p} 0.094)$.

Materials and Methods: Disease-free survival (DFS) and overall survival (OS) were evaluated according to tumor characteristics, based on information retrospectively retrieved from patients' medical records.

Conclusions: Pathological tumor characteristics and nodal status still represent useful tools in treatment selection and follow-up decision making of EBC patients in clinical practice.

\section{INTRODUCTION}

Accounting for $23 \%$ of the total new cases of cancer and $14 \%$ of the total cancer deaths, breast cancer (BC) is the most frequently diagnosed cancer in women worldwide and the second leading cause of cancer-related mortality [1]. The overall 5-year relative survival rate for BC patients has improved from $75.1 \%$ between 1975 and 1977 to $90.0 \%$ from 2001 to 2007 , mainly thanks to improvements in treatment and earlier diagnosis due to the widespread use of mammography [2]. The 5-year relative survival rate for women diagnosed with localized 
BC is approximately $98 \%$, but survival declines to about $84 \%$ for regional involvement and $23 \%$ for distant disease [3]. Even if BC recurrence usually occurs within the first 5 years after diagnosis, relapse may also happen after 5 years: in a retrospective analysis evaluating 2838 patients receiving adjuvant therapy, who remained disease free for 5 years, the 5-year residual risk of recurrence was $7 \%, 11 \%$ and $13 \%$ for stage I, II and III BC, respectively [4]. The risk of metastases and death increases with both BC size at diagnosis and number of axillary lymph nodes involved [5-8]. Tumor grade, hormone receptor status and human epidermal growth factor receptor 2 (HER2) status significantly influence survival [9-11]. In more recent years, (neo-)adjuvant systemic treatment for BC is applied more often and has considerably improved. The introduction of trastuzumab, for instance, significantly increased both short term and long term prognosis in HER2-positive BC patients [12, 13]. Estrogen receptor (ER), progesterone-receptor (PR) and HER2, routinely available in $\mathrm{BC}$ tissue samples and recorded in cancer registries and patients' medical records, are useful tools for therapeutic decision making and could be considered reliable surrogates for the more expensive molecular subtyping [14].

To quantify the effect of traditional prognostic factors, both long term and in the current era, on outcome of $\mathrm{BC}$ patients, we performed a single-center, retrospective survival analysis of women with early invasive $\mathrm{BC}$ treated in clinical practice at our Department, to determine their disease-free survival (DFS) and overall survival (OS) and to design proper follow-up strategies according to risk of recurrence.

\section{RESULTS}

\section{Characteristics of patients and tumors and treatment administered to study population}

Overall, we retrospectively identified 1198 consecutive, early BC patients treated in clinical practice at Medical Oncology Department, San Salvatore Hospital, L'Aquila, Italy, between June 1992 and December 2013.

Main baseline patient and tumor characteristics are reported in Table 1. Specifically, $55.3 \%$ of all tumors had a diameter $\leq 2 \mathrm{~cm}$ (T1) and $52.2 \%$ did not have lymph nodes involvement at the time of surgery (N0). ER $+/ \mathrm{PR} \pm /$ HER2 - tumors accounted for $58.4 \%$ of cases, ER-/PR-/ HER2 - for $10.3 \%, \mathrm{ER}+/ \mathrm{PR} \pm / \mathrm{HER} 2+$ for $9.1 \%$ and $\mathrm{ER}-1$ PR-/HER2+ for $6.3 \%$, while for $15.9 \%$ of samples the IHC pattern was not fully available.

Data on adjuvant treatment administered to study population are summarized in Table 1.

To note, $73 \%$ of patients underwent conservative surgery, $73.5 \%$ received chemotherapy (anthracyclinesbased, 32.8\%; taxanes-based, 11.5\%; anthracyclines and taxanes-based, 23.9\%; not anthracyclines and not taxanesbased, 5.3\%) and $78.5 \%$ endocrine therapy.

\section{Survival analysis}

Median follow-up for the whole patient population was 93 months, being 196 months for the first generation and 85 months for the second generation. Overall, we observed 240 disease recurrences $(20 \%)$, represented by loco-regional relapse in 95 patients $(8 \%)$, contralateral tumor in 31 patients $(2.5 \%)$ and distant metastatic spread in 114 patients $(9.5 \%)$. At the time of data cut-off, 1092 patients $(91.1 \%)$ were still alive and 106 (8.9\%) had died. The overall median DFS was 132 months (95\% Confidence Interval (CI), 3.90 to 4.03 ); the 1-year, 5 -year and 10-year DFS rates were 91\%, 80\% and 52\%, respectively. The overall median OS was 162 months (95\% CI, 4.63 to 4.82); the 1-year, 5-year and 10-year OS rates were $96 \%, 82.5 \%$ and $60.5 \%$, respectively.

The overall median DFS was 92 months (95\% CI, 9.31 to 10.10 ) and 137 months (95\% CI, 4.46 to 4.64 ) for the first and second generation, respectively; the overall median OS was 127 months (95\% CI, 9.33 to 10.10) and 166 months (95\% CI, 5.90 to 6.20$)$, respectively.

\section{Impact of nodal status on survival}

According to the nodal status, patients were classified as N0 (no positive lymph nodes), N1-3 (1-3 positive lymph nodes), N4+ ( $\geq 4$ positive lymph nodes). For 70 patients the nodal status was not available.

The median DFS was 165 months (95\% CI 6.55 to 6.94), 105 months (95\% CI 6.03 to 6.36) and 106 months (95\% CI 12.50 to 13.60 ) for the N0, N1-3 and N4+ subgroups, respectively. At 1 year from diagnosis, 94\% of N0 patients was still disease-free, compared to $91 \%$ of N1-3 and $88 \%$ of N4+ patients; at 5 years, DFS rates were $81 \%, 65.2 \%$ and $63 \%$, respectively; at 10 years, DFS rates were $61.5 \%, 46 \%$ and $42 \%$, respectively. The median OS was 196 months (95\% CI 9.44 to 10.26), 134 months (95\% CI 6.64 to 7.04$)$ and 151 months (95\% CI 15.62 to 17.34) for the N0, N1-3 and N4+ subgroups, respectively. At 1 year from diagnosis, $96 \%$ of N0 patients, $96 \%$ of N1-3 and $91 \%$ of N4+ patients was still alive; at 5 years, OS rates were $86.4 \%, 80.4 \%$ and $77 \%$, respectively; at 10 years, OS rates were $68.5 \%, 53.4 \%$ and $52.4 \%$, respectively. Figure 1 shows Kaplan-Meier estimates of DFS and OS according to nodal status. DFS and OS rates according to nodal status are shown in Table 2.

Both median DFS and OS were not significantly different between N1-3 and N4+ subgroups (DFS: 95\% CI 0.64 to 1.22, Hazard Ratio (HR) 0.89, p 0.489; OS: $95 \%$ CI 0.61 to 1.28 , HR 0.89, p 0.542). So, data on N1-3 and $\mathrm{N} 4+$ subgroups were collected together in the category $\mathrm{N}+$ and compared to N0 subgroup. Median DFS of N+ 
Table 1: Descriptive characteristics of the study population $(N=1198)$ and treatment administered

\begin{tabular}{|c|c|}
\hline Characteristics & $n(\%)$ \\
\hline \multicolumn{2}{|l|}{ Age (years) } \\
\hline median & 55 \\
\hline range & $24-83$ \\
\hline \multicolumn{2}{|l|}{ Histology } \\
\hline ductal & $846(71.2)$ \\
\hline lobular & 257 (21.6) \\
\hline other & $86(7.2)$ \\
\hline \multicolumn{2}{|l|}{ Tumor size } \\
\hline $\mathrm{T} 1$ & $663(55.3)$ \\
\hline $\mathrm{T} 2$ & $402(33.6)$ \\
\hline $\mathrm{T} 3$ & $44(3.7)$ \\
\hline $\mathrm{T} 4$ & $31(2.6)$ \\
\hline unknown & $58(4.8)$ \\
\hline \multicolumn{2}{|l|}{ Nodal status } \\
\hline No & $625(52.2)$ \\
\hline N1 & 355 (29.6) \\
\hline $\mathrm{N} \geq 2$ & $148(12.4)$ \\
\hline unknown & $70(5.8)$ \\
\hline \multicolumn{2}{|l|}{ Grading } \\
\hline G1 & $130(10.8)$ \\
\hline $\mathrm{G} 2$ & $364(30.4)$ \\
\hline G3 & $569(47.5)$ \\
\hline unknown & 135 (11.3) \\
\hline \multicolumn{2}{|c|}{ Hormone receptor/HER2 status (second generation, $N=1096$ ) } \\
\hline $\mathrm{ER}+/ \mathrm{PR} \pm / \mathrm{HER} 2-$ & $640(58.4)$ \\
\hline ER-/PR-/HER2- & $113(10.3)$ \\
\hline $\mathrm{ER}+/ \mathrm{PR} \pm / \mathrm{HER} 2+$ & $100(9.1)$ \\
\hline ER-/PR-/HER2+ & $69(6.3)$ \\
\hline not fully available & $174(15.9)$ \\
\hline \multicolumn{2}{|l|}{ Surgery } \\
\hline conservative & $875(73)$ \\
\hline radical & $323(27)$ \\
\hline \multicolumn{2}{|l|}{ Chemotherapy } \\
\hline yes & $881(73.5)$ \\
\hline anthracyclines-based & $393(32.8)$ \\
\hline taxanes-based & $138(11.5)$ \\
\hline anthracyclines and taxanes-based & $286(23.9)$ \\
\hline not anthracyclines and not taxanes-based & $64(5.3)$ \\
\hline not & $317(26.5)$ \\
\hline \multicolumn{2}{|l|}{ Endocrine therapy } \\
\hline yes & $941(78.5)$ \\
\hline $\begin{array}{c}\text { post-menopausal } \\
\text { tamoxifen }\end{array}$ & $134(11)^{*}$ \\
\hline
\end{tabular}


aromatase-inhibitor

$293(24.5)$

tamoxifen $\rightarrow$ aromatase inhibitor

$101(8)$

pre-menopausal

tamoxifen

$58(5)$

tamoxifen + LH-RH analogue

$209(17.5)$

aromatase-inhibitor $+\mathrm{LH}-\mathrm{RH}$ analogue

$54(4.5)$

tamoxifen $\rightarrow$ aromatase inhibitor (+ LH-RH analogue)

not

\section{Radiotherapy}

yes

not

$279(23.3)$

*This group includes post-menopausal patients treated with endocrine therapy before the introduction of aromatase inhibitors in clinical practice in Italy (about 1997).

patients was 102 months and median OS 134 months. The difference in median DFS between $\mathrm{N} 0$ and $\mathrm{N}+$ subgroups was statistically significant $(95 \%$ CI 0.44 to 0.66 , HR 0.54 , $p<0.0001)$ as well as the difference in median OS $(95 \%$ CI 0.47 to 0.74 , HR 0.59, p 0.0005) (Figure 2).

\section{Impact of hormone receptor/HER2 status on survival}

Survival analysis according to the tumor IHC pattern was performed only for patients of the second generation (HER2 status evaluated). Anyway, for 174 out of 1096 patients of the second generation the full receptor assessment was not available $(n=922)$.

At median follow-up 85 months, patients with $\mathrm{ER}+/ \mathrm{PR} \pm / \mathrm{HER} 2$ - tumors showed a median DFS of 162 months (95\% CI, 13.94 to 14.95$)$ and a median OS of 165 months (95\% CI, 11.36 to 12.35). Patients with ER-/PR-/ HER2- (triple negative, TN) tumors had a median DFS of 92 months (95\% CI, 10.16 to 11.02$)$ and a median OS of 158 months ( $95 \% \mathrm{CI}, 13.78$ to 15.60 ). In particular, in this subgroup, the 1-year and 5-year DFS rates were
$86.5 \%$ and $60 \%$, respectively, with a plateau in the curve starting from about 100 months from diagnosis (8-year DFS, $40 \%$ ); the 1 -year and 5-year OS rates were $96.4 \%$ and $68.7 \%$, respectively.

In the HER2+ subgroup, when both patients treated and not-treated with adjuvant trastuzumab were included, the overall median DFS was 130 months (95\% CI, 11.46 to 12.57 ) and the median OS 157 months (95\% CI, 13.97 to 15.56). According to the hormone receptor status, their outcome was separately evaluated: patients with ER+/ $\mathrm{PR} \pm / \mathrm{HER} 2+$ tumors had a median DFS of 132 months (95\% CI, 16.13 to 18.42 ) and a median OS not reached; patients with ER-/PR-/HER2+ tumors had a median DFS of 91 months ( $95 \%$ CI, 13.95 to 15.82$)$ and a median OS not reached. The analysis of the DFS curves for these subgroups showed that the 2-year and the 5-year DFS rates were $88.7 \%$ and $78 \%$, respectively, for patients with ER+/ $\mathrm{PR} \pm / \mathrm{HER} 2+$ tumors and $72 \%$ and $59 \%$, respectively, for patients with ER-/PR-/HER2+ tumors (Table 3).

When data from HER2+ patients treated and not-treated with adjuvant trastuzumab were separately analyzed, a statistically significant difference in both
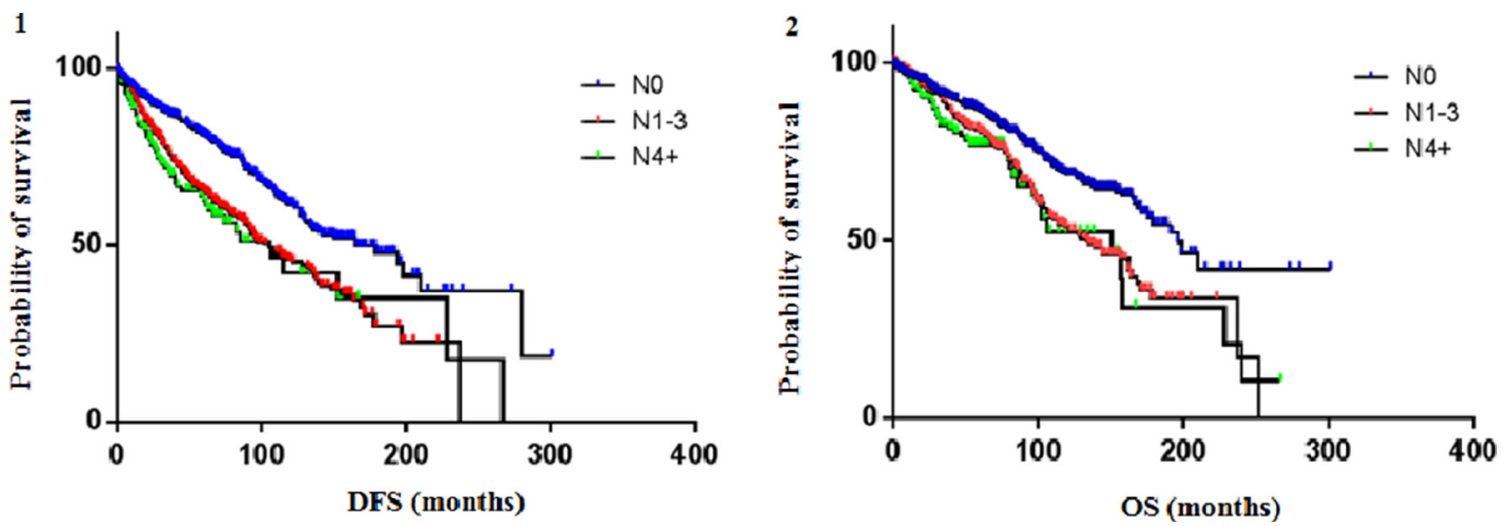

Figure 1: DFS (1) and OS (2) according to nodal status. The median DFS was 165 months (95\% CI 6.55 to 6.94$), 105$ months (95\% CI 6.03 to 6.36$)$ and 106 months (95\% CI 12.50 to 13.60) for the N0, N1-3 and N4+ subgroups, respectively. The median OS was 196 months (95\% CI 9.44 to 10.26), 134 months (95\% CI 6.64 to 7.04 ) and 151 months (95\% CI 15.62 to 17.34 ) for the N0, N1-3 and N4+ subgroups, respectively. 
Table 2: Survival rates according to nodal status

\begin{tabular}{ccccccccc}
\hline & $\begin{array}{c}\text { Median DFS } \\
\text { (months) }\end{array}$ & $\mathbf{2 y}$ & $\mathbf{5 y}$ & $\mathbf{1 0 y}$ & $\begin{array}{c}\text { Median OS } \\
\text { (months) }\end{array}$ & $\mathbf{2 y}$ & $\mathbf{5 y}$ & $\mathbf{1 0 y}$ \\
\hline $\begin{array}{c}\text { Overall } \\
\boldsymbol{n}=\mathbf{1 1 2 8} \\
\quad \mathbf{N 0}\end{array}$ & 132 & 85.6 & 80 & 52 & 162 & 92.8 & 82.5 & 60.5 \\
$\begin{array}{c}\boldsymbol{n}=\mathbf{6 2 5} \\
\mathbf{N 1 - 3} \\
\boldsymbol{n}=\mathbf{3 5 5} \\
\mathbf{N} 4+ \\
\boldsymbol{n}=\mathbf{1 4 8}\end{array}$ & 165 & 89.4 & 81 & 61.5 & 196 & 93.4 & 86.4 & 68.5 \\
\hline
\end{tabular}

Table 3: Survival rates according to hormone receptor/HER2 status (all patients)

\begin{tabular}{|c|c|c|c|c|c|c|c|c|}
\hline & \multirow{2}{*}{$\begin{array}{c}\text { Median } \\
\text { DFS } \\
\text { (months) }\end{array}$} & \multicolumn{3}{|c|}{$\%$ DFS } & \multirow{2}{*}{$\begin{array}{c}\text { Median OS } \\
\text { (months) }\end{array}$} & \multicolumn{3}{|c|}{$\% \mathrm{OS}$} \\
\hline & & $2 y$ & $5 \mathbf{y}$ & $10 y$ & & $2 y$ & $5 y$ & $10 \mathrm{y}$ \\
\hline $\mathrm{ER}+/ \mathrm{PR} \pm / \mathrm{HER} 2-n=640$ & 162 & 87.2 & 76 & 57.5 & 165 & 93 & 84.5 & 61 \\
\hline ER-/PR-/HER2- $n=113$ & 92 & 75 & 60 & 39.3 & 158 & 89.7 & 68.7 & 55.9 \\
\hline $\mathrm{ER}+/ \mathrm{PR} \pm / \mathrm{HER} 2+n=100$ & 132 & 88.7 & 78 & 59 & not reached & 95 & 86.8 & 65 \\
\hline ER-/PR-/HER2 $+n=69$ & 91 & 72 & 59 & 46 & not reached & 89 & 65 & 60 \\
\hline
\end{tabular}

DFS and OS was observed between patients with $\mathrm{ER}+/$ $\mathrm{PR} \pm / \mathrm{HER} 2+$ and ER-/PR-/HER2+ tumors only in the cohort of patients treated with adjuvant trastuzumab. In this cohort, the median DFS was not reached for the $\mathrm{ER}+/ \mathrm{PR} \pm / \mathrm{HER} 2+$ subgroup and 80 months for the ER-/ PR-/HER2+ subgroup (95\% CI 0.16 to 0.73 , HR 0.34 , p 0.0056); the median OS was not reached for both subgroups (95\% CI 0.11 to 0.75 , HR 0.28 , p 0.011). On the other hand, in the cohort of patients not-treated with adjuvant trastuzumab, the median DFS was 132 months for the $\mathrm{ER}+/ \mathrm{PR} \pm / \mathrm{HER} 2+$ subgroup and 97 months for the ER-/PR-/HER2+ subgroup (95\% CI 0.34 to 1.76 , HR $0.77, \mathrm{p} 0.544)$; the median OS was 157 months for the $\mathrm{ER}+/ \mathrm{PR} \pm / \mathrm{HER} 2+$ subgroup and not reached for the ER-/ PR-/HER2+ subgroup (95\% CI 0.38 to 2.22, HR 0.93, p 0.78 ) (Figure 3). Figure 4 shows Kaplan-Meier curves of DFS and OS of all four analyzed subgroups, including in the HER2+ subgroup only patients treated with adjuvant
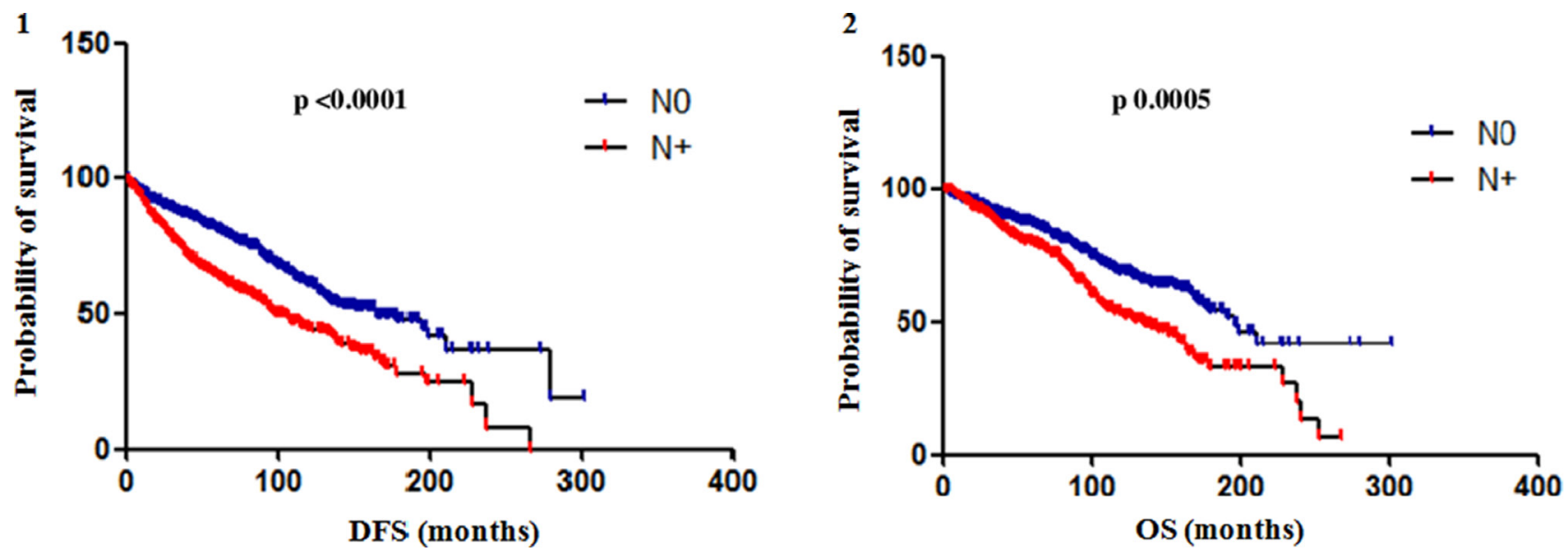

Figure 2: Difference in DFS (1) and OS (2) between N0 and N+ subgroups. The difference in median DFS between N0 and N+ (data on $\mathrm{N} 1-3$ and $\mathrm{N} 4+$ subgroups were collected together in the category $\mathrm{N}+$ ) subgroups was statistically significant (95\% CI 0.44 to 0.66 , HR $0.54, p<0.0001)$ as well as the difference in median OS (95\% CI 0.47 to 0.74 , HR 0.59, p 0.0005). 
trastuzumab: patients with $\mathrm{ER}+/ \mathrm{PR} \pm / \mathrm{HER} 2-$ and $\mathrm{ER}+/$ $\mathrm{PR} \pm /$ HER2+ tumors had a significantly better prognosis than those with TN and ER-/PR-/HER2+ tumors, for both DFS (p 0.0002) and OS (p 0.011).

\section{Impact of the combination of nodal status and hormone receptor/HER2 status on survival}

To better define the impact of both nodal status and IHC tumor pattern on outcome, a combined analysis of survival was performed.

$\mathrm{ER}+/ \mathrm{PR} \pm / \mathrm{HER} 2-$ tumors occurred at diagnosis with no lymph nodes involvement (N0) in 52.4\% of cases $(n=335)$ and with lymph nodes positivity $(\mathrm{N}+)$ in $44.2 \%$ $(n=283)$; in $3.4 \%$ of cases nodal status was not available. TN tumors were N0 at diagnosis in $53.1 \%$ of cases $(n=60)$ and $\mathrm{N}+$ in $37.2 \%(n=42)$; in $9.7 \%$ of cases nodal status was not available. $\mathrm{ER}+/ \mathrm{PR} \pm / \mathrm{HER} 2+$ tumors were N0 at diagnosis in $54 \%$ of cases $(n=54)$ and $\mathrm{N}+$ in $34 \%(n=34)$; in $12 \%$ of cases nodal status was not available. ER-/PR-/ HER2+ tumors were N0 at diagnosis in 39.1\% of cases $(n=27)$ and $\mathrm{N}+$ in $50.7 \%(n=35)$; in $10.2 \%$ of cases nodal status was not available. DFS and OS rates according to node and hormone receptor/HER2 status are shown in Table 4.

\section{Not adjuvant trastuzumab}
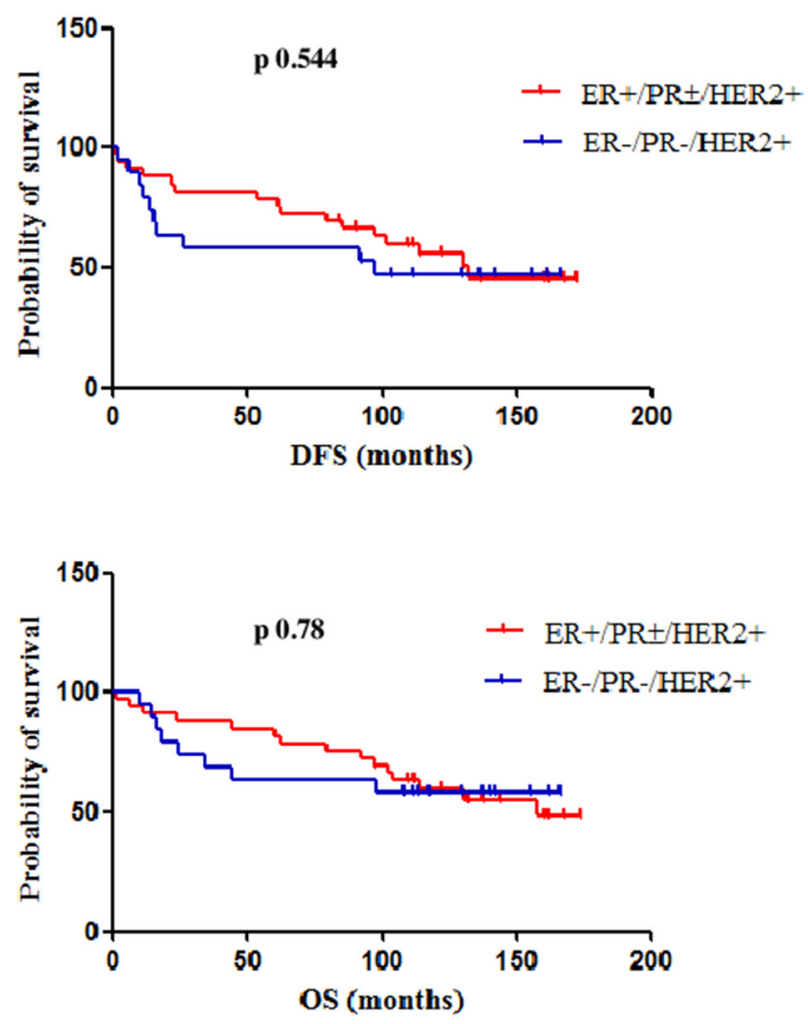

In the $\mathrm{ER}+/ \mathrm{PR} \pm / \mathrm{HER} 2-$ subgroup, median DFS was 165 months and 114 months in case of N0 and N+ tumors, respectively $(p<0.001)$ and median OS 166 months and 144 months, respectively ( $p$ 0.028), with statistically significant differences.

In the TN subgroup, median DFS was 109 months and 65 months in case of N0 and N+tumors, respectively (p 0.144) and median OS 158 months and 96 months, respectively ( $p$ 0.384), with not statistically significant differences, but with a trend toward a poorer prognosis in case of nodal involvement.

In the HER2+ subgroup, a different impact of nodal status can be observed based on the receptor status. Patients with $\mathrm{ER}+/ \mathrm{PR} \pm / \mathrm{HER} 2+$ tumors had a median DFS of 130 months if $\mathrm{N} 0$ and 114 months if $\mathrm{N}+(\mathrm{p} 0.489)$ and a median OS not reached if N0 and of 157 months if $\mathrm{N}+$ (p 0.876), showing differences not statistically significant according to the nodal status. On the other hand, patients with ER-/PR-/HER2+ tumors had a median DFS not reached if $\mathrm{N} 0$ and of 66 months if $\mathrm{N}+(\mathrm{p} 0.009)$ and a median OS not reached neither if $\mathrm{N} 0$ nor if $\mathrm{N}+(\mathrm{p} 0.039)$, with a significant impact of the nodal status on outcome (Table 5). Figure 5 shows Kaplan-Meier curves on DFS according to node and hormone receptor/HER2 status.

\section{Adjuvant trastuzumab}
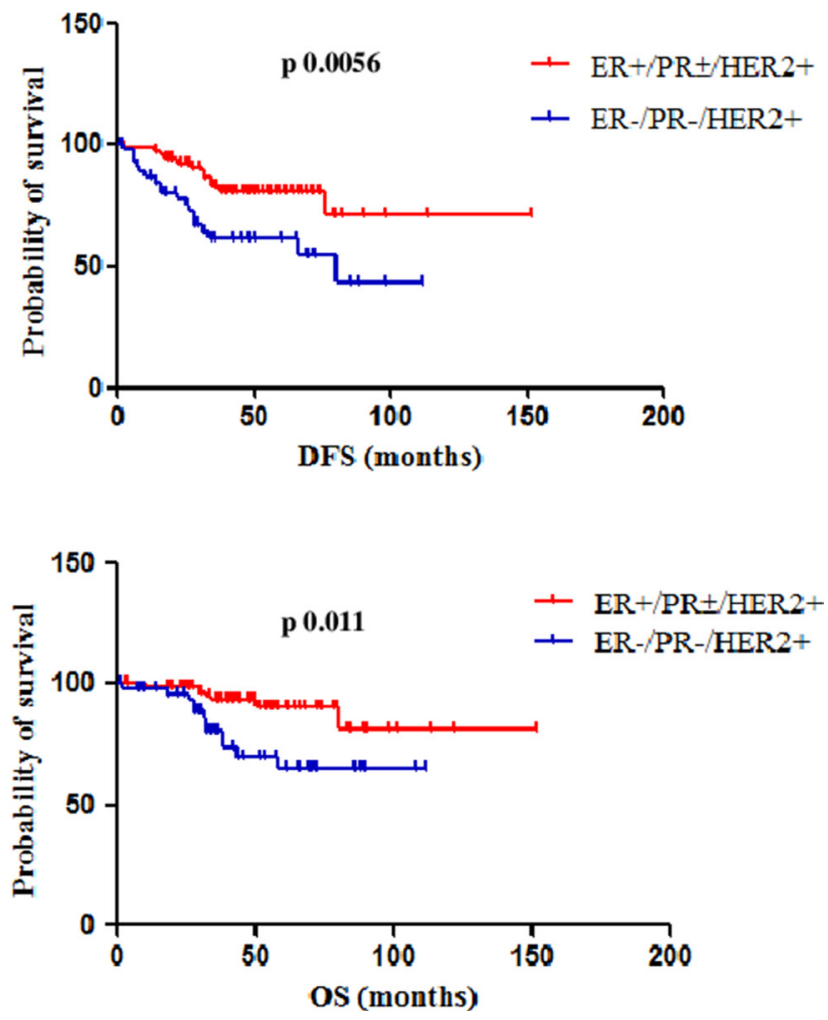

Figure 3: DFS and OS of ER+/PR $\pm / H E R 2+$ and ER-/PR-/HER2+ patients treated and not-treated with adjuvant trastuzumab. A statistically significant difference in both DFS and OS was observed between patients with ER $+/ \mathrm{PR} \pm / \mathrm{HER} 2+$ and $\mathrm{ER}-/$ PR-/HER2 + tumors only in the cohort of patients treated with adjuvant trastuzumab. 
Table 4: Survival rates according to nodal and hormone receptor/HER2 status

\begin{tabular}{|c|c|c|c|c|c|c|c|c|}
\hline & & \multicolumn{3}{|c|}{$\%$ DFS } & \multicolumn{3}{|c|}{$\% \mathrm{OS}$} & \multirow{2}{*}{$\begin{array}{l}\text { Median } \\
\text { follow up } \\
\text { (months) }\end{array}$} \\
\hline & & $2 y$ & $5 y$ & $10 y$ & $2 y$ & $5 y$ & $10 y$ & \\
\hline \multirow{2}{*}{ ER+/PR $\pm /$ HER2- } & No & 89 & 82 & 65.6 & 92 & 87 & 68 & 75 \\
\hline & $\mathbf{N}+$ & 85 & 70 & 47 & 92 & 82 & 55 & 71 \\
\hline \multirow{2}{*}{ ER-/PR-/HER2- } & NO & 82.8 & 68 & 42 & 91.4 & 71.8 & 61.2 & 93 \\
\hline & $\mathbf{N}+$ & 71.8 & 56 & 36.4 & 87.3 & 62.2 & 44.8 & 89 \\
\hline \multirow{2}{*}{ ER+/PR $\pm /$ HER2+ } & No & 92.5 & 80.4 & 57.5 & 96.2 & 87 & 64 & 73 \\
\hline & $\mathbf{N}+$ & 85 & 73 & 49 & 90.9 & 87.3 & 61 & 74 \\
\hline \multirow{2}{*}{ ER-/PR-/HER2+ } & No & 90.7 & 85 & 58.5 & 100 & 95 & 83 & 70 \\
\hline & $\mathbf{N}+$ & 64.3 & 46 & 34.4 & 87 & 56.5 & 56.5 & 65 \\
\hline
\end{tabular}

Table 5: Median DFS and OS according to nodal and hormone receptor/HER2 status

\begin{tabular}{|c|c|c|c|c|c|}
\hline & & $\begin{array}{c}\text { Median DFS } \\
\text { (months) }\end{array}$ & $p$ & $\begin{array}{c}\text { Median OS } \\
\text { (months) }\end{array}$ & $p$ \\
\hline \multirow{2}{*}{ ER+/PR $\pm /$ HER2- } & No & 165 & \multirow{2}{*}{$<0.001$} & 166 & \multirow{2}{*}{0.028} \\
\hline & $\mathbf{N}+$ & 114 & & 144 & \\
\hline \multirow{2}{*}{ ER-/PR-/HER2- } & No & 109 & \multirow{2}{*}{0.144} & 158 & \multirow{2}{*}{0.384} \\
\hline & $\mathbf{N}+$ & 65 & & 96 & \\
\hline \multirow{2}{*}{ ER+/PR $\pm /$ HER2+ } & No & 130 & \multirow{2}{*}{0.489} & not reached & \multirow{2}{*}{0.876} \\
\hline & $\mathbf{N}+$ & 114 & & 157 & \\
\hline \multirow{2}{*}{ ER-/PR-/HER2+ } & No & not reached & \multirow{2}{*}{0.009} & not reached & \multirow{2}{*}{0.039} \\
\hline & $\mathbf{N}+$ & 66 & & not reached & \\
\hline
\end{tabular}
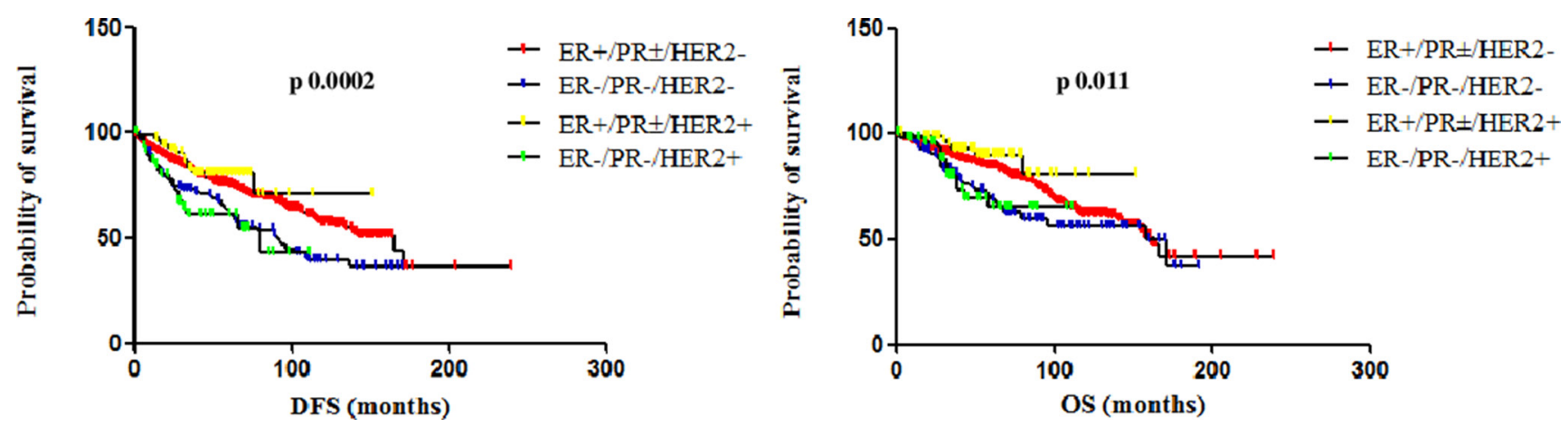

Figure 4: DFS and OS of ER+/PR \pm /HER2-, ER-/PR-/HER2-, ER+/PR $\pm / H E R 2+$ and ER-/PR-/HER2+ (treated with adjuvant trastuzumab). When including in the HER2+ subgroup only patients treated with adjuvant trastuzumab, patients with ER+/ $\mathrm{PR} \pm / \mathrm{HER} 2-$ and $\mathrm{ER}+\mathrm{PR} \pm / \mathrm{HER} 2+$ tumors had a significantly better prognosis than those with $\mathrm{TN}$ and $\mathrm{ER}-/ \mathrm{PR}-/ \mathrm{HER} 2+$ tumors, for both DFS (p 0.0002) and OS (p 0.011). 
A separate analysis was performed to assess the impact of nodal status on outcome in the two different subgroups of patients with HER2+ tumors, according to treatment with adjuvant trastuzumab. Patients with $\mathrm{ER}+/ \mathrm{PR} \pm / \mathrm{HER} 2+$ tumors not-treated with trastuzumab had a median DFS not reached if N0 and 114 months if $\mathrm{N}+(\mathrm{p} 0.297)$ and a median OS not reached if $\mathrm{N} 0$ and of 157 months if $\mathrm{N}+(\mathrm{p} 0.475)$, showing differences not statistically significant according to the nodal status. Also patients with $\mathrm{ER}+/ \mathrm{PR} \pm / \mathrm{HER} 2+$ tumors treated with trastuzumab had median DFS and OS not significantly different based on nodal status: median DFS was 95 months if $\mathrm{N} 0$ and 85 months if $\mathrm{N}+(\mathrm{p}$ 0.615) and median OS was not reached if $\mathrm{N} 0$ and of 106 months if $\mathrm{N}+(\mathrm{p} 0.436)$.

Patients with ER-/PR-/HER2+ tumors not-treated with adjuvant trastuzumab had a median DFS not reached if N0 and 26 months if $\mathrm{N}+(\mathrm{p}$ 0.279) and a median OS not reached if $\mathrm{N} 0$ and of 34 months if $\mathrm{N}+(\mathrm{p}$ 0.273), showing differences not statistically significant according to the nodal status, but with times to disease recurrence shorter than other subgroups. Patients with ER-/PR-/ HER2+ tumors treated with trastuzumab had median DFS significantly different based on nodal status, as median DFS was not reached if N0 and 66 months if $\mathrm{N}+(\mathrm{p} 0.014)$,
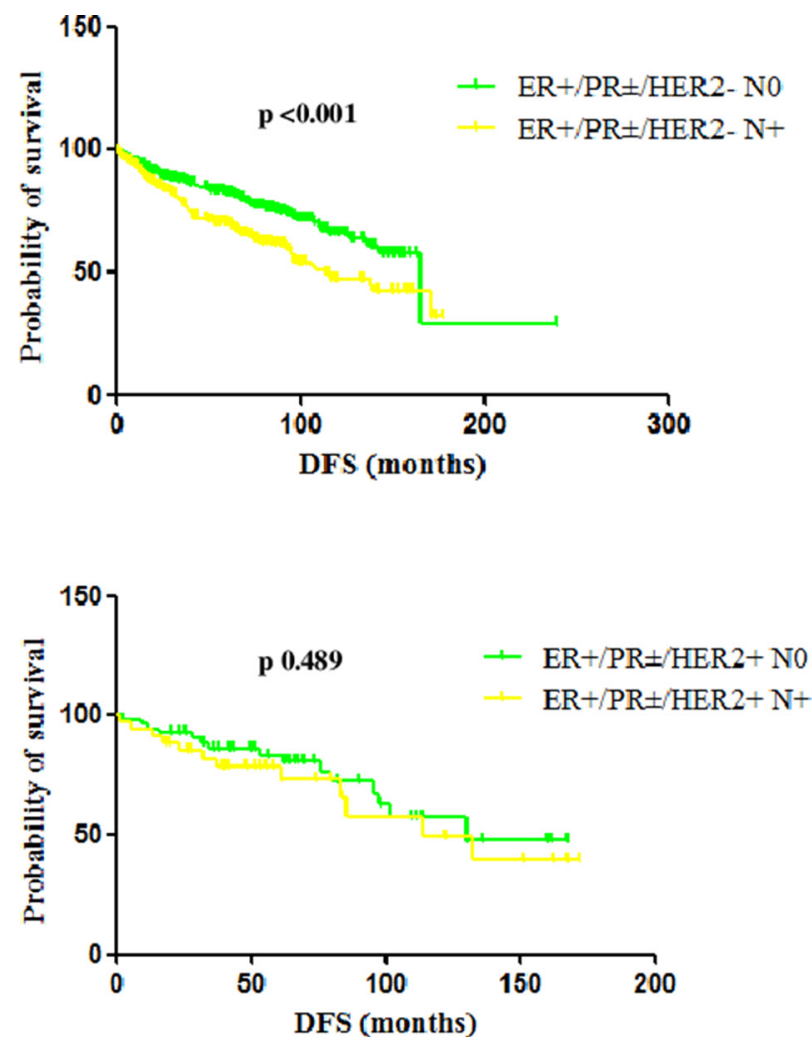

while OS was not reached neither if $\mathrm{N} 0$ nor if $\mathrm{N}+(\mathrm{p} 0.094)$ (Table 6).

\section{DISCUSSION}

In this retrospective analysis, we estimated the role of well established prognostic factors in 1198 early BC patients, over a period of about twenty years. Our findings suggest that nodal status and IHC tumor pattern still represent useful tools in the treatment selection and follow-up decision making of patients in clinical practice. We found a statistically significant difference in both DFS and OS between patients with $\mathrm{N} 0$ and $\mathrm{N}+$ tumors (DFS: 165 versus 102 months; OS: 196 versus 134 months), confirming that lymph node negativity is an important predictor of better long-term outcome in early BC: Colzani et al. [6] found that lymph node negativity at diagnosis was the only independent factor associated with favorable prognosis in these patients and reported that, in agreement with a previous study [15], the effect of lymph node positivity on survival was still evident many years after diagnosis, conferring an increased risk of death even after 10 years. More, they did not detect a statistical difference between having one to three or four or more positive
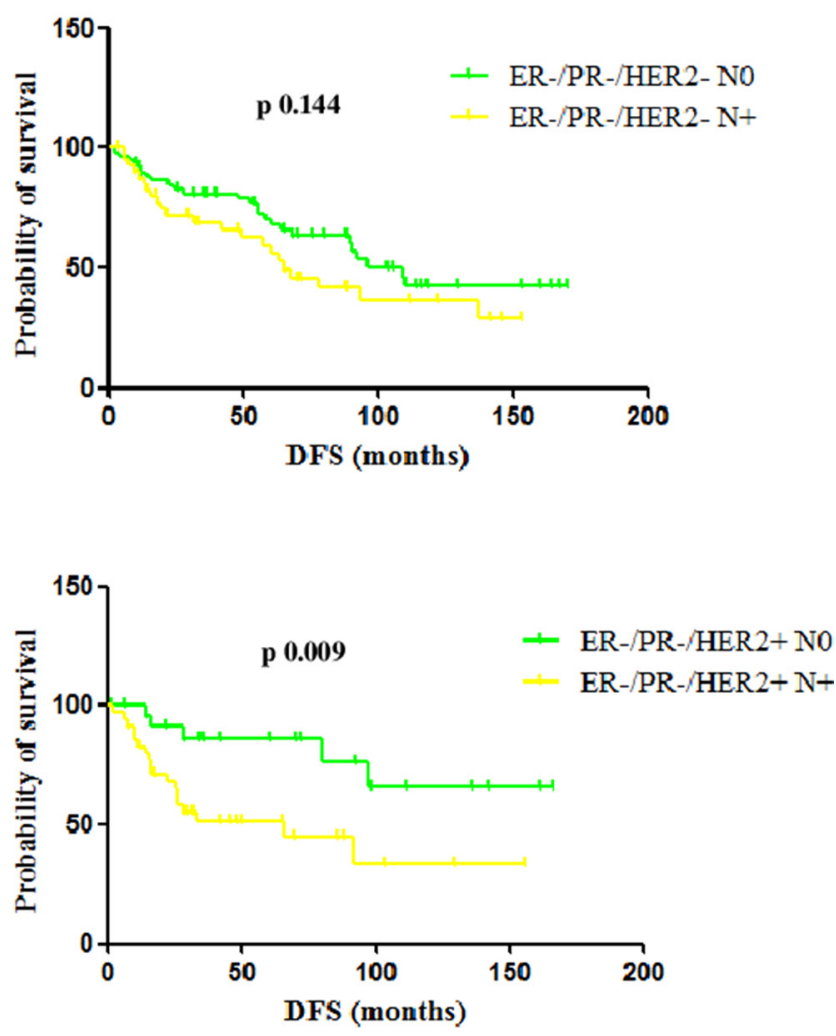

Figure 5: Median DFS according to node and hormone receptor/HER2 status. In the ER+/PR \pm /HER2- subgroup, median DFS was 165 months and 114 months in case of N0 and N+ tumors, respectively $(p<0.001)$. In the TN subgroup, median DFS was 109 months and 65 months in case of N0 and N+ tumors, respectively (p 0.144), with a not statistically significant difference, but with a trend toward a poorer prognosis in case of nodal involvement. Patients with ER+/PR \pm /HER2+ tumors had a median DFS of 130 months if N0 and 114 months if $\mathrm{N}+(\mathrm{p}$ 0.489), while patients with ER-/PR-/HER2+ tumors had a median DFS not reached if N0 and of 66 months if $\mathrm{N}+(\mathrm{p} 0.009)$. 
Table 6: Median DFS and OS according to nodal status and treatment with adjuvant trastuzumab

\begin{tabular}{|c|c|c|c|c|c|}
\hline & & $\begin{array}{c}\text { Median DFS } \\
\text { (months) }\end{array}$ & $p$ & $\begin{array}{c}\text { Median OS } \\
\text { (months) }\end{array}$ & $p$ \\
\hline \multirow{2}{*}{$\begin{array}{l}\text { ER+/PR } \pm / \text { HER2+ } \\
\text { pre-trastuzumab }\end{array}$} & No & not reached & \multirow{2}{*}{0.297} & not reached & \multirow{2}{*}{0.475} \\
\hline & $\mathbf{N}+$ & 114 & & 157 & \\
\hline \multirow{2}{*}{$\begin{array}{l}\mathrm{ER}+/ \mathrm{PR} \pm / \mathrm{HER} 2+ \\
\text { post-trastuzumab }\end{array}$} & No & 95 & \multirow{2}{*}{0.615} & not reached & \multirow{2}{*}{0.436} \\
\hline & $\mathbf{N}+$ & 85 & & 106 & \\
\hline \multirow{2}{*}{$\begin{array}{c}\text { ER-/PR-/HER2+ } \\
\text { pre-trastuzumab }\end{array}$} & No & not reached & \multirow{2}{*}{0.279} & not reached & \multirow{2}{*}{0.273} \\
\hline & $\mathbf{N}+$ & 26 & & 34 & \\
\hline \multirow{2}{*}{$\begin{array}{l}\text { ER-/PR-/HER2+ } \\
\text { post-trastuzumab }\end{array}$} & No & not reached & \multirow{2}{*}{0.014} & not reached & \multirow{2}{*}{0.094} \\
\hline & $\mathbf{N}+$ & 66 & & not reached & \\
\hline
\end{tabular}

lymph nodes among women $\leq 45$ years, but, in the overall analyzed population, they showed that the number of positive lymph nodes was related to survival in the first 5 years after diagnosis, while there was a tendency for the curves to converge thereafter. Consistently with these results, in our findings, although differences in survival between patients with N1-3 and N4 tumors were not statistically significant, the $2 \mathrm{y}, 5 \mathrm{y}$ and $10 \mathrm{y}$-DFS rates show that the probabilities of disease recurrence depend on the number of positive lymph nodes more within the first 5 years after diagnosis ( 2 y-DFS rates: $83.6 \%$ if N1-3; $78.3 \%$ if $\mathrm{N} \geq 4$ ) compared to what happens from 5 years onwards (5 y-DFS rates: $65.2 \%$ if $\mathrm{N} 1-3 ; 63 \%$ if $\mathrm{N} \geq 4$; 10y-DFS rates: $46 \%$ if $\mathrm{N} 1-3 ; 42 \%$ if $\mathrm{N} \geq 4$ ).

Our results show that the greatest impact of lymph node status on survival occurs for the ER+/PR $\pm /$ HER2and ER-/PR-/HER2+ subgroups, where differences in DFS and OS are statistically significant between N0 and $\mathrm{N}+$ cases, while for the TN and $\mathrm{ER}+/ \mathrm{PR} \pm / \mathrm{HER} 2+$ subgroups there is a trend toward better prognosis for N0 cases, but not reaching statistical significance. The explanation of the not significant impact of nodal status among TN BC patients should be sought in the biological aggressiveness of this disease, as argued below. Patients with TN BC showed the worst prognosis in our analysis, reporting the shortest DFS and OS, in line with literature data [16-18]. As previously mentioned, in this subgroup, the 1 -year and 5-year DFS rates were $86.5 \%$ and $60 \%$, respectively, with a plateau in the curve starting from about 100 months from diagnosis (8-year DFS, 40\%). This characteristic pattern of recurrence of TN BC has been already described by Dent et al. [19] who reported that, in their study, the risk of recurrence increased rapidly from diagnosis, reached a peak between 1 to 3 years and then decreased quickly. Consistently, Liedtke et al. showed that, after neoadjuvant chemotherapy, recurrence and death rates for TN BC were strongly time-dependent and higher during the first 3 years after diagnosis [20]. The same phenomenon was observed in a more recent study assessing time of recurrence and factors influencing outcome in patients with TN BC [21]: the highest risk of relapse occurred during the first 3 years after primary treatment and then, during the next 2 years of follow-up, it did not change. The 6-year DFS and OS rates were 68 and $62 \%$, respectively, comparable to our findings. Notably, authors found that the tumor size was responsible for recurrence despite lack of involvement of lymph nodes, while nodal status, together with tumor size, adjuvant/ neoadjuvant treatment and metastases in the brain, liver and bones influenced OS. In a large cohort of patients with TN BC, evaluating the clinical outcomes and the relationship between tumor size, lymph node status and prognosis, the 5 -year OS was $80 \%$ for N0 patients, $65 \%$ for $\mathrm{N} 1-3,48 \%$ for $\mathrm{N} 4-9$, and $44 \%$ for $\mathrm{N} \geq 10$ $(p<0.0001)$; the 5 -year RFS rates were $67 \%$ for N0, $52 \%$ for N1, 36\% for N2, and 33\% for N3 ( $p<0.0001)$. Even if these survival rates are comparable to ours, authors showed that, when comparing $\mathrm{N} 0$ with $\mathrm{N}+$ disease, there was a significant difference in OS and DFS. However, once there was evidence of lymph node metastasis, the prognosis could not be affected by the number of positive lymph nodes [22]. In the TN subgroup, we reported a median DFS 109 months and 65 months in case of N0 and $\mathrm{N}+$ tumors, respectively (p 0.144) and median OS 158 months and 96 months, respectively (p 0.384), with not statistically significant differences, but with a trend toward a poorer prognosis in case of nodal involvement. Thus, in our experience, the nodal status seems not to influence the long-term outcome of patients affected by this poor prognosis disease, making us hypothesize that 
the biological aggressiveness of the disease has a greater impact on prognosis compared to its extension. On the other hand, in the ER+/PR \pm /HER2- subgroup, given the biological less aggressive behavior of the disease, tumor extension could have a major role on prognosis. In this subgroup, in fact, median DFS was 165 months and 114 months in case of N0 and N+ tumors, respectively $(p<0.001)$ and median OS 166 months and 144 months, respectively ( $\mathrm{p}$ 0.028), confirming, among other, their overall better outcome compared to the other subgroups [23]. Clearly, bias related to the retrospective data analysis and to the different type of chemotherapy performed could have had an impact on outcome. The lack of a significant impact of nodal status on prognosis of patients with $\mathrm{ER}+/$ $\mathrm{PR} \pm /$ HER2 $+\mathrm{BC}$ could be due to the effect of endocrine therapy that they received and to its interaction with the intracellular pathway of the HER2 receptor. The hormonereceptor status may influence clinical behavior not only in HER2-negative, but also in HER2-positive BC.

In the HER2+ cohort of our study, we noticed a different prognosis of patients according to hormonereceptor, nodal status (even if significant only for the subgroup of patients with ER-/PR-/HER2+ tumors treated with adjuvant trastuzumab) and treatment with adjuvant trastuzumab, consistent with data of the multicenter observational RETROHER study, where relapse rates at 3 years were higher in case of node-positivity, hormonereceptor negativity and diagnosis in the pre-trastuzumab era [24]. Our data show that, before the introduction of trastuzumab in the therapeutic management, the difference in DFS and OS between hormone-receptor positive and hormone-receptor negative patients is not significant. Anyway, from the survival analysis it is clear that up to 120 months from diagnosis the two curves are separated, while after 120 months they overlap: we hypothesized it may be charged to the carry-over effect of endocrine therapy [25]. It has been recently reported that outcomes in HER2+ patients with early BC not receiving anti-HER2 therapy strongly depend on hormone-receptor expression: in line with our findings, hormone-receptor positive tumors had a slowly decreasing hazard compared to hormone-receptor negative tumors, which showed a higher and more quickly declining hazard of disease-recurrence during follow-up; at about 6 years from diagnosis, the two curves tended to cross [26]. On the other hand, in our series, patients treated with adjuvant trastuzumab showed separated curves with statistically significant differences: trastuzumab deletes the negative prognostic effect of HER2 and the role of hormone-receptor status turns clear. In HER2+ advanced BC, expression of ER, PR or both receptors in $\geq 30 \%$ of tumor cells was significantly associated with an improvement in PFS compared with lower or null expression. In this setting, the administration of maintenance endocrine therapy to patients with hormone-receptor positive tumors led to a significant reduction in the risk of progression compared to patients not receiving endocrine therapy. Interestingly, high hormone receptor expression was associated with a non-significant trend toward reduced risk of progression also in patients not receiving maintenance endocrine therapy [27]. It is now widely recognized that HER2+/ hormone receptor-positive and HER2+/hormone receptornegative tumors fall into two distinct subtypes, carrying a different prognosis in the absence of HER2 targeted therapy [28-29] and that this different clinical behavior can be explained by the molecular mechanisms guiding their biology, mainly represented by the bidirectional and dynamic cross-talk between the HER2 and the hormone receptor pathways [30-31]. The different biology between $\mathrm{ER}+/ \mathrm{PR} \pm / \mathrm{HER} 2+$ and $\mathrm{ER}-/ \mathrm{PR}-/ \mathrm{HER} 2+\mathrm{BC}$ could explain the different impact of nodal status on longterm outcome of affected patients. Our results show that median DFS between node negative and positive patients among the $\mathrm{ER}+/ \mathrm{PR} \pm / \mathrm{HER} 2+$ subgroup is not significantly different, contrarily to what happens among the ER-/PR-/ HER2+ subgroup. As disease recurrences occur later for $\mathrm{ER}+/ \mathrm{PR} \pm / \mathrm{HER} 2+\mathrm{BC}$, regardless of treatment with antiHER2 therapy (as previously argued), we hypothesize that patients in this subgroup have not yet fully matured all their relapse events, also considering that they received endocrine therapy, with its abovementioned carry-over effect.

A bias related to the shorter follow-up of patients with HER2-positive BC treated with trastuzumab also explains why, according to Kaplan-Meier curves (Figure 4), the 10-year DFS and OS of ER+/PR $\pm /$ HER2$\mathrm{BC}$ patients seems worse than $\mathrm{ER}+/ \mathrm{PR} \pm / \mathrm{HER} 2+$. We believe it is due to the fact that, starting from 2006, all recurrences have not yet occurred.

Surely, the present study presents some substantial limitations, mainly related to the retrospective methodology used. Furthermore, in the interpretation of results we also have to consider the heterogeneity of adjuvant treatments delivered, the different follow-up length for the various subgroups (particularly between HER2+ patients treated and not-treated with adjuvant trastuzumab, belonging to sequential and not parallel cohorts) and the small number of patients in some subgroups (especially when the HER2+ cohort was divided according to the hormonal-receptor and nodal status). Finally, the IHC analysis of tumor samples was not centralized, but pulled out from patients' medical records. In particular, we are aware that chemo- and endocrine therapies have greatly improved over the twenty years of retrospective observation, but they transversally involved all BC subtypes. Thus, we believe that data analysis may still be valid. Objective of this study was not to assess the impact of different treatments on prognosis of our patients, but to evaluate how, in clinical practice, the extension and the biology of disease can help us better define the surveillance strategies. Despite these limitations, the strength of this work lies in the analysis of a large series 
of patients, all treated according to the standard of care, over a period of about 20 years and then with a follow-up long enough to capture a large number of recurrences.

In conclusion, the main aim of surveillance after the primary treatment of $\mathrm{BC}$ is the early detection of disease recurrences potentially treatable with radical intent, as well as the monitoring of long-term effects of therapies. We believe that the concept of personalized medicine is to be applied not only to the therapeutic management of patients, but also to the monitoring phase for an adequate follow-up, differentiating, through validated prognostic models, categories at highest risk which may require a more intensive surveillance than lower-risk categories. Our results could be a useful tool helping physicians in their clinical decision making as well as in the selection of the better follow-up strategies for their patients.

\section{MATERIALS AND METHODS}

\section{Ethics statement}

All procedures performed in this study, involving human participants, have been conducted in accordance with the 1964 Helsinki declaration and its later amendments or comparable ethical standards. Written informed consent was obtained from all patients.

\section{Methods}

Present analysis included patients with early invasive $\mathrm{BC}$ treated in the adjuvant setting at Medical Oncology Department, San Salvatore Hospital, L'Aquila, Italy, over a period of about twenty years (from June 1992 to December 2013).

Information on date and age at $\mathrm{BC}$ diagnosis, tumor characteristics, local and systemic therapy, date of local or distant disease recurrence, date of last follow-up and date of death were retrieved from patients' medical records. Staging of primary tumors was based on the TNM pathological cancer staging classification, 7th edition [32]. Tumor stage was defined according to the greatest dimension of the largest tumor size (T1a, $\leq 0.5$ $\mathrm{cm}$ (including micro-invasion); $\mathrm{T} 1 \mathrm{~b},>0.5 \mathrm{~cm}$ and $\leq 1 \mathrm{~cm}$; $\mathrm{T} 1 \mathrm{c},>1 \mathrm{~cm}$ and $\leq 2 \mathrm{~cm} ; \mathrm{T} 2,>2 \mathrm{~cm}$ and $\leq 5 \mathrm{~cm} ; \mathrm{T} 3,>5$ $\mathrm{cm}, \mathrm{T} 4$, any size with direct extension to chest wall and/ or skin). Lymph node status was described according to the number of regional lymph nodes with pathologically proven metastasis, including results of sentinel lymph node excision. Lymph nodes with only isolated tumor cells were defined lymph node negative (N0, no pathologically proven positive lymph nodes; N1, 1-3 positive, N2, 4-9 positive; N3, $\geq 10$ positive). Grading of tumors was based on the AJCC grading system, 7th edition [32]. From 1992 to 1999 , the analysis of ER and PR was performed by the immunocytochemical method (Abbott monoclonal ER-ICA and PG-ICA, for ER and PR, respectively); from 2000 to 2013, the analysis was done with the IHC method, using Dako monoclonal antibodies throughout the entire study period: for ER, ER 1D5 Dako antibody was used from 2000 to 2010 and ER EP1 Dako from 2011 to 2013; for PR, Dako PgR 636 was used from 2000 to 2013. Patients were considered ER-positive and PR-positive in case of $\geq 1 \%$ tumor cells nuclear staining at IHC analysis. HER2 analysis was done using the HercepTest (Dako), with staining intensity score evaluated from 0 to $3+$. For specimens staining 2+, Fluorescent in situ Hybridization analysis was performed to assess HER2 amplification (ratio > 2.2). HER2 status was registered from 1999 and onward. Among enrolled patients, 102 (8.5\%) and 1096 $(91.5 \%)$ received diagnosis of $\mathrm{BC}$ before (first generation) and after 1999 (second generation), respectively.

Among patients from the second generation, two cohorts were analyzed: patients who received adjuvant chemotherapy without trastuzumab, mostly until 2005, and patients who received adjuvant chemotherapy followed by or combined with trastuzumab since 2006, when adjuvant trastuzumab was approved in Italy.

\section{Statistical analysis}

Primary end-point of the study was the evaluation of the DFS and the OS of the whole population and according to tumor characteristics.

DFS was defined as the time from diagnosis of BC to time from surgery to any invasive or non-invasive $\mathrm{BC}$ recurrence, either local, regional, contralateral or distant; $\mathrm{OS}$ was defined as the time from diagnosis of $\mathrm{BC}$ to death from any cause or to last follow-up [33].

Kaplan-Meier curves of DFS and OS were compared by the log-rank test, with statistical significance set at $p \leq 0.05$.

\section{Abbreviations}

BC: breast cancer; HER2: human epidermal growth factor receptor 2; ER: estrogen receptor; PR: progesterone-receptor; DFS: disease-free survival; OS: overall survival; IHC: immunohistochemical; CI: Confidence Interval; HR: Hazard Ratio; TN: triple negative.

\section{Authors' contributions}

Conception and design: Katia Cannita, Valentina Cocciolone, Maria Letizia Calandrella; Development of methodology: Katia Cannita, Valentina Cocciolone, Maria Letizia Calandrella; Provision of study materials or patients: Katia Cannita, Valentina Cocciolone, Enrico Ricevuto, Paola Lanfiuti Baldi, Tina Sidoni, Azzurra Irelli, Stefania Paradisi, Laura Pizzorno, Valter Resta, Alberto Bafile, Edoardo Alesse, Alessandra Tessitore, Corrado Ficorella; Acquisition of data: Maria Letizia Calandrella, 
Valentina Cocciolone, Katia Cannita; Analysis and interpretation of data: Valentina Cocciolone, Katia Cannita, Maria Letizia Calandrella; Writing and revision of the manuscript: Valentina Cocciolone, Katia Cannita, Corrado Ficorella; Final approval of manuscript: All authors.

\section{ACKNOWLEDGMENTS}

None.

\section{CONFLICTS OF INTEREST} interests

The authors declare that they have no competing

\section{FUNDING}

None.

\section{REFERENCES}

1. Jemal A, Bray F. Global Cancer Statistics. CA Cancer J Clin. 2011; 61:69-90.

2. Berry DA, Cronin KA, Plevritis SK, Fryback DG, Clarke L, Zelen M, Mandelblatt JS, Yakovlev AY, Habbema JD, Feuer EJ; Cancer Intervention and Surveillance Modeling Network (CISNET) Collaborators. Effect of screening and adjuvant therapy on mortality from breast cancer. N Engl J Med. 2005; 353:1784-1792.

3. Siegel R, DeSantis C. Cancer treatment and survivorship statistics, 2012. CA Cancer J Clin. 2012; 62:220-241.

4. Brewster AM, Hortobagyi GN, Broglio KR, Kau SW, Santa-Maria CA, Arun B, Buzdar AU, Booser DJ, Valero V, Bondy M, Esteva FJ. Residual risk of breast cancer recurrence 5 years after adjuvant therapy. J Natl Cancer Inst. 2008; 100:1179-1183.

5. Brekelmans CT, Tilanus-Linthorst MM, Seynaeve C, vd Ouweland A, Menke-Pluymers MB, Bartels CC, Kriege M, van Geel AN, Burger CW, Eggermont AM, Meijers-Heijboer $\mathrm{H}$, Klijn JG. Tumour characteristics, survival and prognostic factors of hereditary breast cancer from BRCA2-, BRCA1and non-BRCA1/2 families as compared to sporadic breast cancer cases. Eur J Cancer. 2007; 43:867-76.

6. Colzani E, Liljegren A, Johansson AL, Adolfsson J, Hellborg H, Hall PF, Czene K. Prognosis of patients with breast cancer: causes of death and effects of time since diagnosis, age, and tumor characteristics. J Clin Oncol. 2011; 29:4014-21.

7. De Boer M, van Dijck JA, Bult P, Borm GF, Tjan-Heijnen VC. Breast cancer prognosis and occult lymph node metastases, isolated tumor cells, and micrometastases. J Natl Cancer Inst. 2010; 102:410-25.
8. Tan LK, Giri D, Hummer AJ, Panageas KS, Brogi E, Norton L, Hudis C, Borgen PI, Cody HS 3rd. Occult axillary node metastases in breast cancer are prognostically significant: results in 368 node-negative patients with 20-year followup. J Clin Oncol. 2008; 26:1803-9.

9. Simpson JF, Gray R, Dressler LG, Cobau CD, Falkson CI, Gilchrist KW, Pandya KJ, Page DL, Robert NJ. Prognostic value of histologic grade and proliferative activity in axillary node-positive breast cancer: results from the Eastern Cooperative Oncology Group Companion Study, EST 4189. J Clin Oncol. 2000; 18:2059-69.

10. Bardou VJ, Arpino G, Elledge RM, Osborne CK, Clark GM. Progesterone receptor status significantly improves outcome prediction over estrogen receptor status alone for adjuvant endocrine therapy in two large breast cancer databases. J Clin Oncol. 2003; 21:1973-9.

11. Pritchard KI, Shepherd LE, O'Malley FP, Andrulis IL, Tu D, Bramwell VH, Levine MN; National Cancer Institute of Canada Clinical Trials Group. HER2 and responsiveness of breast cancer to adjuvant chemotherapy. N Engl J Med. 2006; 354:2103-11.

12. Romond EH, Perez EA, Bryant J, Suman VJ, Geyer CE Jr, Davidson NE, Tan-Chiu E, Martino S, Paik S, Kaufman PA, Swain SM, Pisansky TM, Fehrenbacher L, et al. Trastuzumab plus adjuvant chemotherapy for operable HER2-positive breast cancer. N Engl J Med. 2005; 353:1673-84.

13. Perez EA, Romond EH, Suman VJ, Jeong JH, Sledge G, Geyer CE Jr, Martino S, Rastogi P, Gralow J, Swain SM, Winer EP, Colon-Otero G, Davidson NE, et al. Trastuzumab plus adjuvant chemotherapy for human epidermal growth factor receptor 2-positive breast cancer: planned joint analysis of overall survival from NSABPB-31 and NCCTG N9831. J Clin Oncol. 2014; 32:3744-52.

14. Goldhirsch A, Wood WC, Coates AS, Gelber RD, Thürlimann B, Senn HJ; Panel members. Strategies for subtypes--dealing with the diversity of breast cancer: highlights of the St. Gallen International Expert Consensus on the Primary Therapy of Early Breast Cancer 2011. Ann Oncol. 2011; 22:1736-47.

15. Warwick J, Tabàr L, Vitak B, Duffy SW. Time-dependent effects on survival in breast carcinoma: Results of 20 years of follow-up from the Swedish Two-County Study. Cancer. 2004; 100:1331-1336.

16. Kaplan HG, Malmgren JA. Impact of triple negative phenotype on breast cancer prognosis. Breast J. 2008; 14:456-63.

17. Nishimura R, Arima N. Is triple negative a prognostic factor in breast cancer? Breast Cancer. 2008; 15:303-8.

18. Mersin H, Yildirim E, Berberoglu U, Gulben K. The prognostic importance of triple negative breast carcinoma. Breast. 2008; 17:341-6.

19. Dent R, Trudeau M, Pritchard KL, Hanna WM, Kahn HK, Sawka CA, Lickley LA, Rawlinson E, Sun P, Narod SA. 
Triple-negative breast cancer: clinical features and patterns of recurrence. Clin Cancer Res. 2007; 13:4429-34.

20. Liedtke C, Mazouni C, Hess KR, André F, Tordai A, Mejia JA, Symmans WF, Gonzalez-Angulo AM, Hennessy B, Green M, Cristofanilli M, Hortobagyi GN, Pusztai L. Response to neoadjuvant therapy and long-term survival in patients with triple-negative breast cancer. J Clin Oncol. 2008; 26:1275-81.

21. Pogoda K, Niwińska A, Murawska M, Pieńkowski T. Analysis of pattern, time and risk factors influencing recurrence in triple-negative breast cancer patients. Med Oncol. 2013; 30:388.

22. Hernandez-Aya LF, Chavez-Macgregor M, Lei X, MericBernstam F, Buchholz TA, Hsu L, Sahin AA, Do KA, Valero V, Hortobagyi GN, Gonzalez-Angulo AM. Nodal status and clinical outcomes in a large cohort of patients with triplenegative breast cancer. J Clin Oncol. 2011; 29:2628-34.

23. Blows FM, Driver KE, Schmidt MK, Broeks A, van Leeuwen FE, Wesseling J, Cheang MC, Gelmon K, Nielsen TO, Blomqvist C, Heikkilä P, Heikkinen T, Nevanlinna H, et al. Subtyping of breast cancer by immunohistochemistry to investigate a relationship between subtype and short and long term survival: a collaborative analysis of data for 10,159 cases from 12 studies. PLoS Med. 2010; 7:e1000279.

24. Vici P, Pizzuti L, Natoli C, Moscetti L, Mentuccia L, Vaccaro A, Sergi D, Di Lauro L, Trenta P, Seminara P, Santini D, Iezzi L, Tinari N, et al. Outcomes of HER2positive early breast cancer patients in the pre-trastuzumab and trastuzumab eras: a real-world multicenter observational analysis. The RETROHER study. Breast Cancer Res Treat. 2014; 147:599-607.

25. Howell A. The endocrine prevention of breast cancer. Best Pract Res Clin Endocrinol Metab. 2008; 22:615-23.

26. Strasser-Weippl K, Horick N, Smith IE, O'Shaughnessy J, Ejlertsen B, Boyle F, Buzdar AU, Fumoleau P, Gradishar W, Martin M, Moy B, Piccart-Gebhart M, Pritchard KI, et al. Long-term hazard of recurrence in HER2+ breast cancer patients untreated with anti-HER2 therapy. Breast Cancer Res. 2015; 17:56.
27. Montemurro F, Rossi V, Cossu Rocca M, Martinello R, Verri E, Redana S, Adamoli L, Valabrega G, Sapino A, Aglietta M, Viale G, Goldhirsch A, Nolè F. Hormone-receptor expression and activity of trastuzumab with chemotherapy in HER2-positive advanced breast cancer patients. Cancer. 2012; 118:17-26.

28. Perou CM, Sorlie T, Eisen MB, van de Rijn M, Jeffrey SS, Rees CA, Pollack JR, Ross DT, Johnsen H, Akslen LA, Fluge O, Pergamenschikov A, Williams C, et al. Molecular portraits of human breast tumours. Nature. 2000; 406: 747-752.

29. Sorlie T, Perou CM, Tibshirani R, Aas T, Geisler S, Johnsen H, Hastie T, Eisen MB, van de Rijn M, Jeffrey SS, Thorsen T, Quist H, Matese JC, et al. Gene expression patterns of breast carcinomas distinguish tumor subclasses with clinical implications. Proc Natl Acad Sci U S A. 2001; 98:10869-10874.

30. Montemurro F, Di Cosimo S, Arpino G. Human epidermal growth factor receptor 2 (HER2)-positive and hormone receptor-positive breast cancer: new insights into molecular interactions and clinical implications. Ann Oncol. 2013; 24: 2715-2724.

31. Arpino G, Wiechmann L, Osborne CK, Schiff R. Crosstalk between the estrogen receptor and the HER tyrosine kinase receptor family: molecular mechanism and clinical implications for endocrine therapy resistance. Endocr Rev. 2008; 29: 217-233.

32. American Joint Committee on Cancer. AJCC Cancer Staging Manual. 7th ed. New York, NY: Springer; 2010.

33. Hudis CA, Barlow WE, Costantino JP, Gray RJ, Pritchard KI, Chapman JA, Sparano JA, Hunsberger S, Enos RA, Gelber RD, Zujewski JA. Proposal for standardized definitions for efficacy end points in adjuvant breast cancer trials: the STEEP system. J Clin Oncol. 2007; 25:2127-32. 